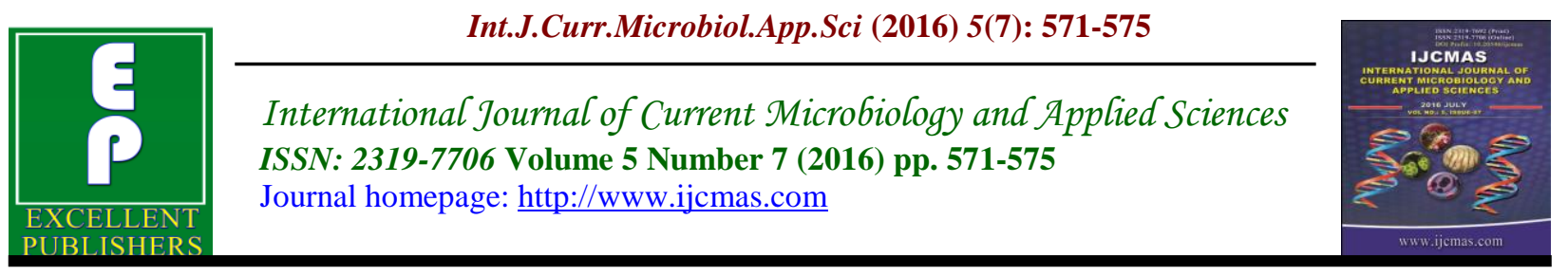

Original Research Article

http://dx.doi.org/10.20546/ijcmas.2016.507.063

\title{
Synergistic Effect of Xylose and Sucrose Enhance Accumulation of Stilbenes in Endophytic Fungus: Aspergillus stellatus
}

\author{
Chetana Roat* and Meenu Saraf \\ Department of Microbiology \& Biotechnology, University School of Sciences, Gujarat \\ University, Ahmedabad-380 009, India \\ *Corresponding author
}

\begin{tabular}{|c|c|}
\hline & A B S T R A C T \\
\hline & \multirow{4}{*}{$\begin{array}{l}\text { The aim of the work presented was to determine the stilbenes accumulation } \\
\text { in fungal cultures of Aspergillus stellatus at different sugars xylose, } \\
\text { maltose, fructose, glucose, galactose and sucrose on mycological medium } \\
\text { Czapek Dox. Xylose and sucrose were selected for maximum accumulation } \\
\text { of stilbenes in the fungal culture. Four concentrations of xylose and sucrose: } \\
1030,50 \text { and } 70 \mathrm{~g}^{-1} \text { were analysed and studied that Xylose showed } \\
\text { maximum production at } 30 \mathrm{~g} \cdot 1^{-1} \text { with } 591 \mu \mathrm{g} \mathrm{g}^{-1} \text { dry mass (DM) of stilbenes } \\
\text { and sucrose produced } 617 \mu \mathrm{g} \mathrm{g}^{-1} \mathrm{DM} \text { of stilbenes at } 50 \mathrm{~g} \cdot 1^{-1} \text {.In different } \\
\text { experiment, their interaction were studied, } 50 \mathrm{gL}^{-1} \text { of xylose and sucrose } \\
\text { marked enhanced in stilbene accumulation with } 773 \mu \mathrm{g} \mathrm{g}^{-1} \mathrm{DM} \text { at } 12 \text { day. }\end{array}$} \\
\hline $\begin{array}{l}\text { Endophytic fungus, } \\
\text { Aspergillus } \\
\text { stellatus } \\
\text { Xylose, Sucrose, } \\
\text { Stilbenes. }\end{array}$ & \\
\hline Article Info & \\
\hline $\begin{array}{l}\text { Accepted: } \\
\text { 20 June } 2016 \\
\text { Available Online: } \\
\text { 10 July } 2016\end{array}$ & \\
\hline
\end{tabular}

\section{Introduction}

Endophytes are chemical synthesizer inside plants grow intra-and/or intercelullarly in the tissues of any part of the plants without causing over symptoms on the plants in which they live, and have proven to be rich sources of bioactive natural products $\mathrm{Li}$ et al., 2008; Tan et al., 2001). The endophytes may provide protection and survival conditions to their host plant by producing a plethora of substances which, once isolated and characterized, may also have potential for use in neutraceutical, pharmaceutical areas (Strobel et al., 2004; Strobel et al., 2003).

Bioactive natural compounds produced by endophytes have been promising potential usefulness in safety and human health concerns, although there is still a significant demand of drug industry for synthetic products due to economic and timeconsuming reasons.

Endophytes provide a broad variety of bioactive secondary metabolites with unique structure, including alkaloids, benzopyranones, chinones, flavonoids, phenolic acids, quinones, steroids, terpenoids, tetralones, xanthones, and others. Such bioactive metabolites find wideranging application as agrochemicals, antibiotics, immunosuppressants, antiparasitics, antioxidants, and anticancer 
agents (11). Polyphenolics like stilbenes are associated with many health benefits that include antioxidant, anti-cancer and antiatherosclerosis properties (Waffo et al., 2008; Baur et al., 2006; Delmas et al., 2006). Phytoalexins from the Vitaceae constitute a rather restricted group of polyphe-nolic secondary metabolites belonging to the stilbenes family (piceid, resveratrol, viniferin, ampelopsin). In the present communication, report the synergestic effect of Xylose and sucrose on stilbenes accumulation in endophytic cultures of Aspergillus stellus.

\section{Materials and Methods}

\section{Endophytic cell cultures}

Alternaria $s p$. was grown at $28{ }^{\circ} \mathrm{C}$ on Czapek Dox medium (CD) plates for 5 days and then prepared into a spore suspension of $1 \times 107$ spores $/ \mathrm{mL}$ (measured using a hemacytometer) by washing the culture with sterile water. A 2-mL aliquot of the spore suspension was inoculated into $100 \mathrm{~mL}$ liquid Czapek dox broth (CDB) in a 250-mL flask and cultivated at $28{ }^{\circ} \mathrm{C}$ in a rotary shaker $(120 \mathrm{rpm})$. After 4 days, the cells were collected by centrifugation at $1,136 \times \mathrm{g}$ for $10 \mathrm{~min}$ at $4{ }^{\circ} \mathrm{C}$ using a refrigerated. The cells were washed twice with sterile water and used to produce stilbenes throughout the study.

Three different experiments were conducted, First all sugars Xylose, Maltose, Fructose, Galactose, Glucose and Sucrose of same concentration $30 \mathrm{gL}^{-1}$ were used, second selected the best two sugars at different concentration $10,30,50,70 \mathrm{gL}^{-1}$ and in third studied the interaction of selected sugars xylose and sucrose. All Sugars were added in the Czapek Dox medium and were coautoclaved with the medium at $121^{\circ} \mathrm{C}$ for 15 $\min$.

\section{Sample preparation}

The cell cultures were harvested after 12 days of treatment, washed with distilled water and filtered under mild vacuum. The cells were weighed to obtain the fresh weight per $100 \mathrm{ml}$ medium Fresh Weight (FW) and dry mass (DM) was then determined by drying the cells powder in liquid nitrogen to a constant weight. Dried homogenized cells $(50 \mathrm{mg})$ were extracted in acetone-water 3:2 (v/v) for $12 \mathrm{~h}$ (room temperature) on a test tube rotator, centrifuged at Relative centrifugal force (RCF) 750 for $15 \mathrm{~min}$ and then the supernatant was concentrated under vacuum at 40LC till the complete removal of acetone, the aqueous extract was partitioned twice with equal amount of ethyl acetate; finally the ethyl acetate phase was concentrated under vacuum till dryness. All the residues were redissolved in HPLC grade methanol and analyzed by using HPLC (pump L2130, auto sampler L-2200, FL detector L-2485, Merck-Hitachi). In brief, separation was accomplished on a (LichroCART) $25094 \mathrm{~mm}$ LiChro-spher (5 lm) RP-18 column protected by a guard column of the same material. The solvent system used was: Solvent A- $0.0025 \%$ trifluoroacetic acid in water; solvent B-80\% acetonitrile (E. Merck, India) in solvent A. The mobile phase consisted of solvent (A) and (B). The step gradient programme of solvent B was as follows: 0-3 min: $14-18 \%$; 3-12 min: $18-18 \%$; 12-25 min: $18-22 \%$; 25-30 min: $22-22 \%$; 30-38 min: $22-40 \%$; 38-43 min: 40-40\%; 43-46 min: 40-60\%; 46-48 min: $60-70 \%$; 48-50 min: 70-70\%; 50-52 min:70-80\%; 52-54 min: 80-80\%; 54-56 min: 80-85\%; 56-58 min: $85-100 \%$; 58-60 min: 100-100\%; 60-62 min: 100$14 \%$; 62-65 min: 14-14\%. Separation was performed at a flow rate of $1.0 \mathrm{ml} \mathrm{min} \mathrm{m}^{-1}$ and chromatographic peaks were monitored at $\mathrm{k}_{\mathrm{exc}} 300 \mathrm{~nm}$ and $\mathrm{k}_{\mathrm{em}} 390 \mathrm{~nm}$ (Krisa et al., 
1999). The spent medium was extracted with $100 \mathrm{ml}$ ethyl acetate and analyzed by HPLC for stilbenes released in the medium.

Standard all the four compound resveratrol, viniferin, piceid and ampelopsin were purchased from Sigma Chemical Co. (St Louis, MO, USA) These were dissolved in methanol to yield a final concentration of $1.0 \mathrm{mg} \mathrm{ml}^{-1}$ and standard curve were prepared using all the standards with concentrations ranging from 50 to $500 \mathrm{ng}$ $\mathrm{ml}^{-1}$. The amount of the other compounds was calculated on the basis of all the four standard compounds.

\section{Statistical analysis}

All results were averaged over two separate analyses from two flasks for the estimation of stilbenes and two consecutive experiments with six replicate flasks in each treatment for growth value determination. The results were expressed as $\mu \mathrm{g} \mathrm{g}^{-1}$ dry mass.

\section{Results and discussion}

\section{Effect of Sugars}

Maltose, xylose, fractose, galactose ,glucose and sucrose of $30 \mathrm{gL}^{-1}$ were found stilbenes accumulation 198, 591,190, 287,92 and 617 $\mu \mathrm{g} \mathrm{g}^{-1} \mathrm{DM}$ in the culture medium (Table 1) Sucrose was given highest accumulation stilbenes $617 \mu \mathrm{g} \mathrm{g}^{-1}$ DM followed by Xylose $591 \mu \mathrm{g} \mathrm{g}^{-1}$ DM. Xylose and sucrose were selected and studied their intraction of 1 $, 3,5,7 \%$ concentrations in the culture medium a. Xylose of $3 \%$ concentration produced maximum stilbene production 591 $\mu \mathrm{g} \quad \mathrm{g}^{-1}$ DM while sucrose of $5 \%$ concentration produced maximum stilbene production $786 \mu \mathrm{g} \mathrm{g}^{-1} \mathrm{DM}$ in Czapek Dox medium (Table 2 and 3 ).All the concentration from (1 to $7 \%$ ) of both the sugars were added together in the Czapek dox medium observed that the $5 \%$ concentration accumulate maximum stilbenes in the cell culture while dry mass of cell was found more in $3 \% 7.2\left(\mathrm{~g} \mathrm{~L}^{-1}\right)$ as compare to $5 \%$ where dry mass was observed $7.0\left(\mathrm{~g} \mathrm{~L}^{-1}\right)$, suggested that growth of cell is not proportional for the production of stilbenes (Table 4). Maximum stilbenes accumulation (4361 $\mathrm{g}^{-1}$ ) was recorded in the cells grown in the medium supplemented with $5 \%$ of xylose and sucrose. When these two sugars were combined, the accumulation and yield were more as compare to the individual sugar.

Our study showed that Xylose being effective at a $5 \%$ and sucrose at 3\% concentration for accumulation of stilbenes but both were independent of cell growth. The influence of carbon concentrations on fungi has been extensively studied (Godinho and Fox, 1981, Griffin, 1994, Cho et al., 2002, Suhr et al., 2002 ).

\begin{tabular}{|c|c|c|c|c|c|c|c|}
\hline \multirow[t]{2}{*}{ Sugars(3\%) } & \multirow[t]{2}{*}{$\mathrm{DM}\left(\mathrm{g} \mathrm{l}^{-1}\right)$} & \multicolumn{6}{|c|}{ stilbenes content $\mu \mathrm{g} \mathrm{g}^{-1} \mathrm{DM}$} \\
\hline & & Piceid & Resveratrol & Viniferin & Ampelopsin & Total & Yield $\mu \mathrm{g} \mathrm{l}^{-1} \mathrm{DM}$ \\
\hline Maltose & $1.7 \pm 0.2$ & $42 \pm 0.5$ & $22 \pm 0.1$ & $56 \pm 0.9$ & $78 \pm 5.3$ & 198 & 337 \\
\hline Xylose & $4.6 \pm 3$ & $55 \pm 4$ & $20 \pm 2$ & $198 \pm 4$ & $318 \pm 2$ & 591 & 2719 \\
\hline Fructose & $2.6 \pm 3$ & $35 \pm 4$ & $11 \pm 2$ & $48 \pm 4$ & $96 \pm 2$ & 190 & 494 \\
\hline Galactose & $1.3 \pm 0.1$ & $79 \pm 2$ & $31 \pm 0.8$ & $102 \pm 8$ & $75 \pm 5$ & 287 & 373 \\
\hline Glucose & $1.2 \pm 1$ & $29 \pm 1$ & $13 \pm 4$ & $21 \pm 3$ & $29 \pm 2$ & 92 & 110 \\
\hline Sucrose & $5.5 \pm 0.0$ & $40 \pm 4$ & $46 \pm 2$ & $199 \pm 2$ & $332 \pm 5$ & 617 & 3394 \\
\hline
\end{tabular}




\begin{tabular}{|c|c|c|c|c|c|c|c|}
\hline \multirow[t]{2}{*}{ Xylose (\%) } & \multirow[t]{2}{*}{$\mathrm{DM}\left(\mathrm{g} \mathrm{l}^{-1}\right)$} & \multicolumn{6}{|c|}{ stilbenes content $\mu \mathrm{g} \mathrm{g}^{-1} \mathrm{DM}$} \\
\hline & & Piceid & Resveratrol & Viniferin & Ampelopsin & Total & Yield $\mu \mathrm{g} \mathrm{l}^{-1} \mathrm{DM}$ \\
\hline 1 & $2.6 \pm 0.2$ & $52 \pm 0.5$ & $24 \pm 0.1$ & $88 \pm 0.9$ & $118 \pm 5.3$ & 282 & 733 \\
\hline 3 & $4.6 \pm 3$ & $55 \pm 4$ & $20 \pm 2$ & $198 \pm 4$ & $318 \pm 2$ & 591 & 2719 \\
\hline 5 & $3.6 \pm 3$ & $55 \pm 4$ & $20 \pm 2$ & $98 \pm 4$ & $110 \pm 2$ & 283 & 1019 \\
\hline 7 & $3.3 \pm 0.1$ & $79 \pm 2$ & $31 \pm 0.8$ & $140 \pm 8$ & $135 \pm 5$ & 385 & 1271 \\
\hline
\end{tabular}

Table 3 Effect of different concentration of sucrose on cell culture growth and stilbenes production in the Aspergillus stellatus after 12 days cultures in Czapek yeast extract agar medium

\begin{tabular}{llllllll}
\hline Sucrose (\%) & DM $\left(\mathrm{g} \mathrm{l}^{-1}\right)$ & \multicolumn{5}{c}{ stilbenes content $\mu \mathrm{g} \mathrm{g}^{-1} \mathrm{DM}$} \\
\cline { 3 - 7 } 1 & & Piceid & Resveratrol & Viniferin & Ampelopsin & Total & Yield $\mu \mathrm{g} \mathrm{l^{-1 }} \mathrm{DM}$ \\
3 & $3.4 \pm 0.1$ & $32 \pm 1$ & $133 \pm 4$ & $114 \pm 1$ & $343 \pm 6$ & 622 & 2114 \\
$\mathbf{5}$ & $5.5 \pm 0.0$ & $40 \pm 4$ & $46 \pm 2$ & $199 \pm 2$ & $332 \pm 5$ & 617 & 3394 \\
7 & $\mathbf{6 . 0} \pm \mathbf{0 . 2}$ & $\mathbf{8 5} \pm \mathbf{0 . 9}$ & $\mathbf{8 7} \pm \mathbf{3}$ & $\mathbf{2 1 3} \pm \mathbf{1}$ & $\mathbf{4 0 1} \pm \mathbf{8}$ & $\mathbf{7 8 6}$ & $\mathbf{4 7 1 6}$ \\
& $3.1 \pm 3$ & $36 \pm 2$ & $40 \pm 3$ & $108 \pm 4$ & $288 \pm 2$ & 472 & 1463 \\
\hline
\end{tabular}

Table 4 Combined effect of different concentration of Maltose and Sucrose on cell culture growth and stilbenes production in the Aspergillus stellatus after 12 days cultures in Czapek yeast extract agar medium

\begin{tabular}{|c|c|c|c|c|c|c|}
\hline \multirow[t]{2}{*}{ Xylose (\%) } & \multirow[t]{2}{*}{ sucrose $(\%)$} & \multicolumn{5}{|c|}{ stilbenes content $\mu \mathrm{g} \mathrm{g}^{-1} \mathrm{DM}$} \\
\hline & & $\mathrm{DM}\left(\mathrm{g} \mathrm{l}^{-1}\right)$ & Piceid & Resveratrol & Viniferin & Ampelopsin \\
\hline 1 & 1 & $6.1 \pm 0.6$ & $68 \pm 2$ & $43 \pm 0.3$ & $103 \pm 0.3$ & $144 \pm 0.5$ \\
\hline 3 & 3 & $7.2 \pm 0.4$ & $100 \pm 8$ & $66 \pm 6$ & $101 \pm 3$ & $138 \pm 20$ \\
\hline 5 & 5 & $7.0 \pm 0.3$ & $126 \pm 2$ & $94 \pm 0.6$ & $196 \pm 5$ & $357 \pm 5$ \\
\hline 7 & 7 & $5.8 \pm 0.3$ & $52 \pm 7$ & $46 \pm 5$ & $78 \pm 8$ & $92 \pm 14$ \\
\hline
\end{tabular}

The obtained results of this study revealed that the mycelial weight, colony diameter and secondary metabolites of A.stellatus significantly affected with the sugars concentrations.

Sucrose proved to be the most promising carbon source to produce bioactive compounds. This explains that a fungal sp may have the ability to utilize a particular carbon source for vegetative growth but may not be able to use it for production of specialized structural molecules. Carbon source promote primary metabolism and feeding with more slowly metabolizable compounds may lead to the formation of secondary products. There is usually a dilemma between achieving maximal cell growth rates and maximal production because conditions that allow fast cell growth could be unfavorable to metabolite production (Arora et al., 2010) This also proves that Czapek dox's medium is most effective for metabolite production responsible for Stilbenes production. This shows that the growth medium can also have a significant effect on secondary metabolites and enhancement of secondary metabolites can only be achieved through systematic manipulation of parameters.

\section{Acknowledgements}

The authors acknowledge the financial support obtained from Department of Biotechnology, Government of India, New Delhi, India for providing DBT BioCARe Women Scientist Fellowship under Grant 
Ref. BT/Bio-CARe/03/420/2012 \& 03-092013 and Gujarat University where the Research work has been conducted.

\section{References}

Arora, D.S., Chandra, P. 2010. Assay of Antioxidant Potential of Two Aspergillus Isolates By Different Methods Under Various PhysioChemical Conditions. Braz $J$ Microbiol., 41(3): 765-777.

Baur, J., Sinclair, D.A. 2006. Therapeutic potential of resveratrol : the invivo evidence. Nat. Rev. Drug Disc., 5: 493-506.

Cho, Y.J., Hwang, H.J., Kim, S.W., Song, C.H., Yun, J.W. 2002. Effect of carbon source and aeration rate on broth rheology and fungal morphology during red pigment production byPaecilomyces sinclairii in a batch bioreactor. J. Biotechnol., 25: 95(1); 13-23.

Delmas, D., Lancon, A., Colin, D., Jannin, B., Latrufe, N. 2006. Resveratrol as a chemopreventive agent: a promising molecule for fighting cancer. Curr. Drug Targets, 7: 423-442

Krisa S, Larronde F, Budzinski H, Decendit A, Deffieux G, Merillon JM (1999)
Stilbenes production by Vitis vinifera cell suspension cultures: methyl jasmonate induction and $13 \mathrm{C}$ biolabeling. J Nat Prod 62:1688-1690

Li, J., G.Z. Zhao, H.H. Chen et al., 2008. "Antitumour and antimicrobial activities of endophytic streptomycetes from pharmaceutical plants in rainforest," Lett. Appl. Microbiol., vol. 47, no. 6, pp. 574-580.

Strobel, G., Daisy, B. 2003. "Bioprospecting for microbial endophytes and their natural products," Microbiol. Mol. Biol. Rev., vol. 67, no. 4, pp. 491-502. Strobel, G., Daisy, B., Castillo, U., Harper, J. 2004. "Natural products from endophytic microorganisms," $J$. Natural Products, vol. 67, no. 2, pp. 257-268.

Tan, R.X., Zou, W.X. 2001. "Endophytes: a rich source of functional metabolites," Natural Product Reports, vol. 18, no. 4, pp. 448-459.

Waffo-Teguo, P., Krisa, S., Richard, T., Merillon, J.M. 2008. Grapevine Stilbenes and their biological effects. In: Bioactive molecules and medicinal plants, Springer, Heidelberg. pp 24-55.

\section{How to cite this article:}

Chetana Roat and Meenu Saraf. 2016. Synergistic Effect of Xylose and Sucrose Enhance Accumulation of Stilbenes in Endophytic Fungus: Aspergillus stellatus. Int.J.Curr.Microbiol.App.Sci. 5(7): 571-575. doi: http://dx.doi.org/10.20546/ijcmas.2016.507.063 